Check for updates

Cite this: RSC Adv., 2017, 7, 56602

Received 18th September 2017 Accepted 12th November 2017

DOI: $10.1039 / \mathrm{c} 7 \mathrm{ra10307g}$

rsc.li/rsc-advances

\section{The effect of doping graphene oxide on the structure and property of polyimide-based graphite fibre $\dagger$}

\author{
Meng Xiao, (iD) a $\mathrm{Na} \mathrm{Li},(\mathbb{D})^{a}$ Zhaokun Ma, (D) *a Huaihe Song, (D) ${ }^{a}$ Kang Lu, (D) ${ }^{a}$ Ang Li, (D) \\ Yuchen Meng, (D) a Dingling Wang (D) and Xi Yan ${ }^{b}$
}

Herein, graphite fibres were prepared from polyimide (PI) fibres by doping varying contents of graphene oxide (GO) into polyimide (PI) fibres through a carbonization and graphitization process. By in situ polymerization, GO/polyamic acid (PAA) was synthesized and used for preparing GO/PI fibres via dry-jet wet spinning. During the spinning process, the molecular orientation of GO/PI fibres was forced to follow the fibre axis under the strong sheer force at the spinneret. The DSC results show that the exothermic intensity of $1.0 \mathrm{wt} \% \mathrm{GO} / \mathrm{PI}$ composite fibres declined by $69.7 \%$ than that of the pure PI fibre; this prevented the breakage of $\mathrm{PI}$ molecular chains and maintained the preferred orientation of the GO/ PI fibres. During the graphitization process, GO sheets were reduced to grain graphene, acting as nucleus crystals, which could enlarge the size of microcrystals of graphite and increase the degree of graphitization. PI fibres as a carbon precursor showed great potential in the preparation of graphite fibres with high thermal conductivity, and GO doping can improve the thermal conductivity of the composite graphite fibres. When $2.0 \mathrm{wt} \% \mathrm{GO}$ was added, the thermal conductivity of the GO/PI composite graphite fibre could reach $435 \mathrm{~W} \mathrm{~m}^{-1} \mathrm{~K}^{-1}$, which was twice that of the pure PI-based graphite fibre.

\section{Introduction}

With the increasing energy density of electronic devices, electronic devices are generating a large amount of heat when in use. If the heat does not conduct to the environment immediately, the temperature of electronic devices will increase, and this may even cause security issues. To conduct heat quickly, we need high thermal conductivity materials (TCMs). Metals have been used as traditional TCMs due to their high thermal conductivity; however, since they are heavy, inflexible, and have relatively high thermal expansion coefficients, they are not ideal for cooling silicon-based electronic devices. ${ }^{1}$ Carbon materials,

${ }^{a}$ State Key Laboratory of Chemical Resource Engineering, Key Laboratory of Carbon Fiber and Functional Polymers Ministry of Education, Beijing Key Laboratory of Electrochemical Process and Technology for Materials, Beijing University of Chemical Technology, Beijing, 100029, P. R. China.E-mail: mazk@mail.buct.edu.cn; Fax: +86-10-6443-4916; Tel: +86-139-1112-6076

${ }^{b}$ Key Laboratory of Carbon Materials, Institute of Coal Chemistry, Chinese Academy of Sciences, Taiyuan, 030001, P. R. China

$\dagger$ Electronic supplementary information (ESI) available: FT-IR spectrum of PAA and GO/PAA fibres. TG and DSC curves of PAA fibres and GO/PAA composite fibres. TG and DSC curves of GO/PI composite fibres. XRD spectrum of GO/PI composite fibres with different GO contents. The element composition of composite graphite fibre with $0.3 \mathrm{wt} \%$ GO content at different heat treating temperature. Tensile modulus of graphite fiber with different content of GO. Thermal conductivity of GO/PI based carbon fibres and graphite fibres with different GO content. TEM of the cross-section and longitudinal-section of graphite fiber with $2.0 \mathrm{wt} \%$ GO content. See DOI: 10.1039/c7ra10307g due to their unique electron structures that have both $\mathrm{sp}^{2}$ and $\mathrm{sp}^{3}$ hybrid orbitals and unique phonon heat conduction mechanism, are very likely to produce high TCMs. ${ }^{2}$

Among various carbon precursors, aromatic polyimide (PI) with different chemical structures can be easily graphitized at a relatively high temperature above $2200{ }^{\circ} \mathrm{C}$ and changed into a highly crystalline graphite structure. ${ }^{3,4}$ Graphite films derived from PMDAODA-type PI films can obtain an ultrahigh thermal conductivity of $1700 \mathrm{~W} \mathrm{~m}^{-1} \mathrm{~K}^{-1}$ in the plane direction. ${ }^{5}$ Many researchers have studied the influence of chemical structure, ${ }^{6,7}$ drawing ratio, ${ }^{8,9}$ and heat-treating ${ }^{\mathbf{1 0}}$ conditions on the performance of graphite films. Various identification methods ${ }^{\mathbf{1 1}, \mathbf{1 2}}$ have been used to illustrate the mechanism of pyrolysis strategy of polyimide films, and the behaviour of polyimide films has also been examined., ${ }^{6,13-15}$

PI fibres are a class of high performance polymer fibres, which are used mainly in heat resistance areas such as high temperature dust removal and flame-retardant protective clothing. Researchers have found that PI fibres can be transformed into graphite fibres with thermal conductivity higher than that of PAN-based carbon fibres through simple heat treatment. ${ }^{16,17} \mathrm{Li}$ Ang et al. found that both the degree of graphitization and thermal conductivity of PIbased graphite fibres were improved with an increase in the heat treating temperature. ${ }^{\mathbf{8 , 1 9}}$ Zhang et al. studied the structure evolution of polyimide fibres with different chemical structures during the carbonization process and discovered that the carbon yield and graphitization degree depended strongly on the chemical structure of the PI fibre. ${ }^{20}$ 
Graphene (GO)/polymer composites have been widely studied due to their excellent properties and high solubility of GO. ${ }^{21,22}$ Graphite oxide (GO) ${ }^{23}$ consists of a two-dimensional graphene sheets with a number of oxygen functional groups, such as hydroxyl, epoxide, and carbonyl groups, at its edges and basal planes. ${ }^{23-25}$ Substituted with oxygen functional groups, GO dissolved well in water and other polar solvents such as DMF, DMAc etc. Via in situ polymerization, GO sheets can combine with the polymer chains due to van der Waals forces. ${ }^{26}$ When the polymer chains attach to the large planer sheets of GO, the orientation of the composite material can be improved by optimizing the orientation of GO sheets., ${ }^{\mathbf{1 , 2 4} 27}$ Ting Huang et al. conducted detailed investigations to illustrate that an optimized orientation of GO in the composite material could enhance the performance and increase the thermal stability of the composite materials. ${ }^{28}$ Chen minghua $^{29}$ found that the mechanical property, thermal conductivity, and electric conductivity clearly increased with the addition of a small amount of GO. Dong et $a l .{ }^{30}$ prepared GO/ PI composite fibres with ODA-modified GO and found that the incorporation of graphene greatly improved the thermal stability and hydrophobic behaviour of the composite fibre. Wang et $a .^{24}$ fabricated GO/PI composite films via in situ polymerization and found that the Young's modulus of the GO/PI composite films was 15 times greater and the tensile strength was 9 times greater than those of the pure PI films.

Herein, we prepared graphite fibres by doping different contents of GO in polyimide. Doping of GO improved the orientation of the GO/PI composite fibre during the spinning process. The TG-DSC curves indicate that addition of GO can increase the thermal stability and reduce exothermic intensity during carbonization such that the preferred molecular orientation of carbon fibres can be maintained. GO sheets acted as crystals during the carbonization and graphitization process and increased the degree of graphitization of the PI/GO-based graphite fibre. After graphitization at $2800{ }^{\circ} \mathrm{C}$, the mechanical property and thermal conductivity improved. When $2.0 \mathrm{wt} \% \mathrm{GO}$ was added, the thermal conductivity of the GO/PI composite graphite fibres could reach $435 \mathrm{~W} \mathrm{~m}^{-1} \mathrm{~K}^{-1}$, which was twice that of the pure PI-based graphite fibre.

\section{Experimental}

\section{Materials}

Natural graphite was purchased from Qingdao Graphite Co., Ltd. Pyromellitic dianhydride (PMDA) and 4,4-oxydianiline (4,4ODA) were purchased from Sinopharm Chemical Reagent Co., Ltd. and sublimated under vacuum at $110{ }^{\circ} \mathrm{C}$ for 5 h. $N^{\prime}, N$ Dimethylacetamide (DMAc) was purchased from Tianjin Guangfu fine chemical Research Institute.

\section{Preparation of the graphene oxide/polyamic acid (GO/PAA) solution}

As shown in Scheme 1, GO was prepared via the modified Hummers method and then dispersed in $N^{\prime}, N$-dimethylacetamide (DMAC) via ultrasonic dispersion. The GO/PAA solution
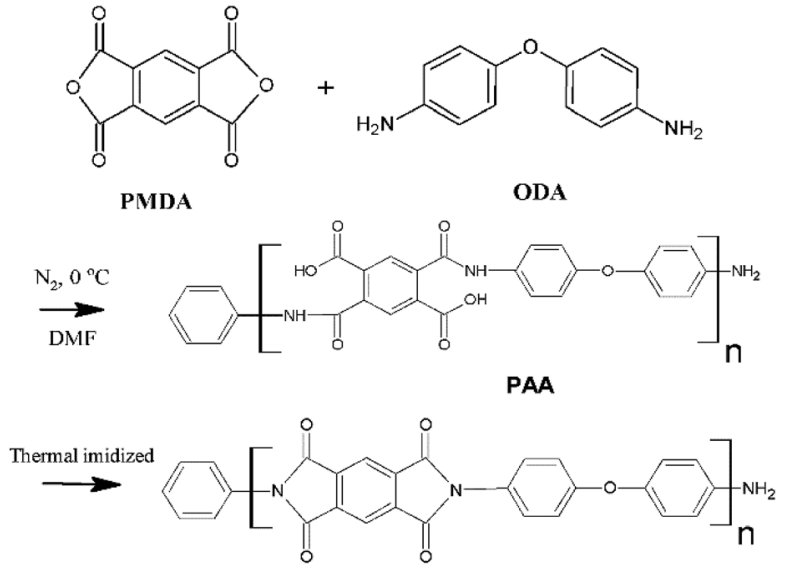

Polyimide

Scheme 1 Schematic for the preparation of PMDA/ODA type polyimide.

was synthesized by dissolving 4,4-oxydianiline (4,4-ODA) in GO dispersion and then adding an equimolar amount of pyromellitic dianhydride (PMDA) gradually. The solution was then stirred at $0{ }^{\circ} \mathrm{C}$ for $2 \mathrm{~h}$ under the atmosphere of pure nitrogen, having a concentration of $15 \mathrm{wt} \%$ in DMAc. The GO/PAA solution, as shown in Fig. 2(a), was degassed at a low temperature to remove the gas in the solution and obtain a homogeneous solution.

\section{Preparation of the graphite oxide/polyimide (GO/PI)} composite fibre

As shown in Scheme 2(a), the GO/PAA fibres were fabricated by extruding the GO/PAA solution through the spinneret (single hole, $0.2 \mathrm{~mm}$ in diameter) using high-pressure nitrogen into a coagulation bath of $10 \%$ ethanol water. The temperature of the coagulation bath is in the range from $25{ }^{\circ} \mathrm{C}$ to $40{ }^{\circ} \mathrm{C}$. The GO/PAA fibres were obtained through a spinning roller. The pressure of nitrogen and the speed of the roller were controlled to decrease the diameter of the GO/PAA fibres. The GO/PAA fibres were tensioned and put in a vacuum environment to remove the solvent in the fibres. The GO/PI fibres were obtained by heating the GO/PAA fibres at $100{ }^{\circ} \mathrm{C}, 200^{\circ} \mathrm{C}$, and $300^{\circ} \mathrm{C}$, with each stage holding for one hour at a heating rate of $5{ }^{\circ} \mathrm{C}$ per minute..$^{31,32}$

\section{Carbonization and graphitization of the GO/PI composite fibre}

The prepared GO/PI fibres were put into corundum crucibles and covered by a graphite sheet to reduce the shrinkage of the fibre. As shown in Scheme 2(b), the GO/PI fibres were carbonized at $1200{ }^{\circ} \mathrm{C}$ in high-purity nitrogen for 1 hour at a heating rate for $5{ }^{\circ} \mathrm{C}$ per minute. Then, the GO/PI-based carbon fibres were graphitized at $2800{ }^{\circ} \mathrm{C}$ in high-purity argon for 1 hour at a heating rate of $10{ }^{\circ} \mathrm{C}$ per minute to obtain GO/PI-based graphite fibres. 
$\mathbf{a}$
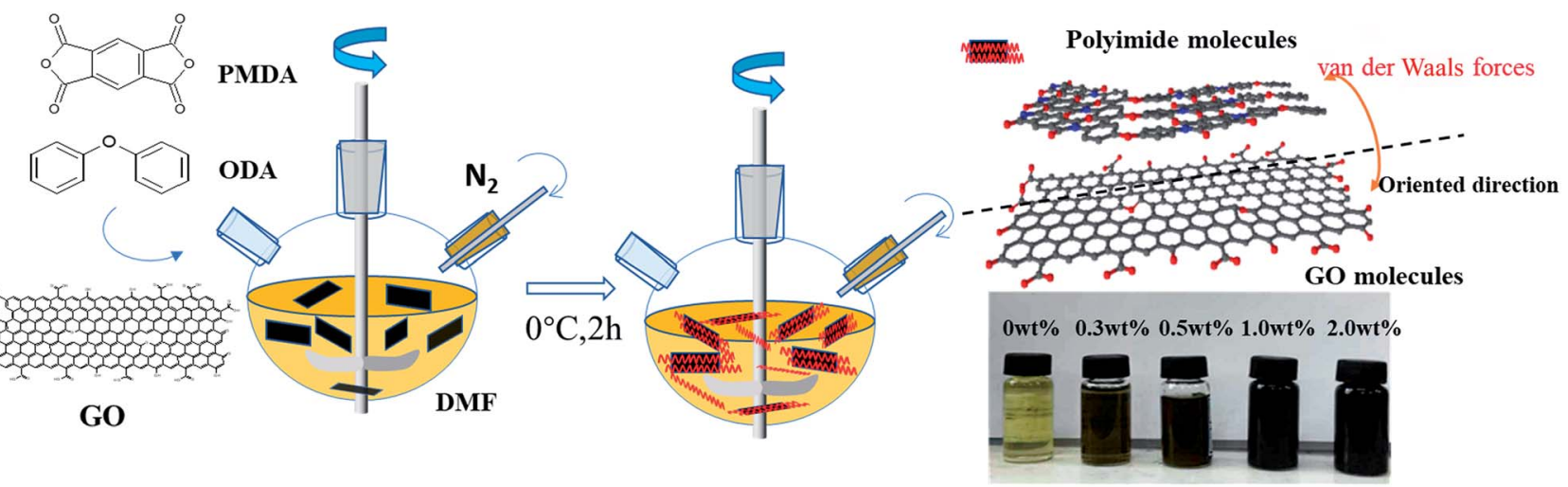

b

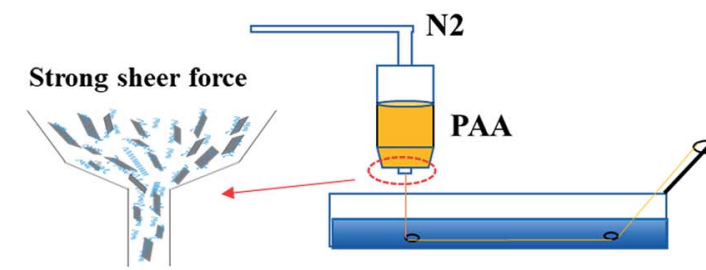

Preferred Orientation

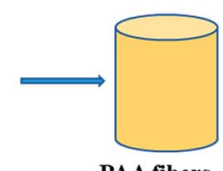

PAA fibers

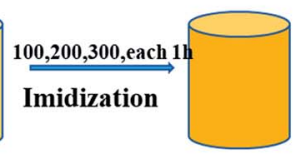

PI fibers

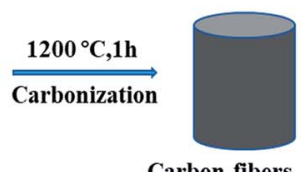

Carbon fibers

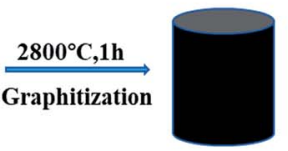

Graphite fibers

Dry-jet wet spinning process

Scheme 2 (a) Preparation of the GO/PAA solutions and (b) preparation of the GO/PI-based graphite fibres.

\section{Characterization}

\section{Fourier transform infrared (FTIR) spectroscopy}

Fourier transform infrared spectroscopy (FTIR, Thermo Nicolet IS50 Series) was used to investigate the molecular structure and chemical bonding groups of the GO/PI composite fibres with attenuated total reflectance in the range from 4000 to $650 \mathrm{~cm}^{-1}$.

\section{Scanning electron microscopy (SEM)}

An SEM (Zeiss Supra 55) operating at $20 \mathrm{kV}$ was used to observe the surface and cross-section morphologies of the GO/PI-based graphite fibre. The graphite fibres were aligned along the same direction and embedded in epoxy resin. Then, the samples were put in liquid nitrogen and quickly broken into two pieces to investigate the morphology of the cross-section. All the samples were treated by gold-spray before observation.

\section{Thermal gravimetric analysis (TG)/differential scanning calorimetry (DSC)}

The Thermal Sync Analyzer (NETZSCH STA 499C, German) was used to investigate the thermal stability of the GO/PAA fibres and GO/PI fibres. The TG/DSC curves were obtained by heating the samples from room temperature to $1000{ }^{\circ} \mathrm{C}$ under a highpurity argon atmosphere at a heating rate of $5{ }^{\circ} \mathrm{C}$ per minute. The calibrated baseline was obtained before sample measurement, and the samples were tested under the same conditions.

\section{X-ray diffraction (XRD)}

The crystalline structure of the graphite fibre was examined by X-ray diffraction (XRD) using a diffractometer (X'Pert Pro, Analytical Co., Ltd). The diffracted intensity of $\mathrm{Cu} \mathrm{K} \alpha$ radiation ( $\kappa 0.1542 \mathrm{~nm} ; 40 \mathrm{kV}$ and $40 \mathrm{~mA}$ ) was measured between 5 and $90^{\circ}$. We used $2 \theta$ to represent the position of the (002) diffraction peak.

According to the Bragg's equation, we can obtain the average interlayer spacing of $d_{002}$.

$$
\lambda=2 d \sin \theta
$$

According to the Scherrer formula, the average size of the crystallite $L_{\mathrm{a}}$ and the average crystallite thickness $L_{\mathrm{c}}$ can be calculate as follows:

$$
\begin{aligned}
& L_{\mathrm{a}}=\frac{0.89 \lambda}{B \cos \theta} \\
& L_{\mathrm{c}}=\frac{0.45 \lambda}{B \sin \theta}
\end{aligned}
$$

$B$ represents the full wave at half maximum (FWHM) of the $d_{002}$ peak.

According to the Mering-Maire empirical formula, the graphitization degree of graphite fibres can be calculated as follows:

$$
G=\frac{0.344-d_{002}}{0.344-0.3354} \times 100 \%
$$


Herein, the average interlayer spacing of the ideal graphite crystal is $0.3354 \mathrm{~nm}$, and the average interlayer spacing of amorphous carbon is $0.344 \mathrm{~nm}$.

\section{Raman}

A laser Raman spectrometer (LabRam HR800, Horiba Jobin Yvon Inc.) was used to investigate the structure of GO/PI-based graphite fibres in the scanning range of $0-4000 \mathrm{~cm}^{-1}$. The degree of graphitization can be represented by the value $R$, which is calculated by the formula $R=I_{\mathrm{D}} / I_{\mathrm{G}}$. The smaller the $R$ value, the higher the degree of graphitization.

\section{Mechanical property of the graphite fibre}

The mechanical property date of the composite carbon fibres was obtained by the single fibre testing method (YG001A, Taicang Instrument Corp. of China) according to the ASTM standard D3544-76 procedure. The average tensile strength and elongation at break were obtained by testing 50 single filaments for each set.

\section{Thermal conductivity of the graphite fibre}

The Shangtai EC430 resistivity meter was used to measure the electrical resistivity of the composite carbon fibre; for each sample, it was measured 30 times to obtain an average value. In our study, the thermal conductivity of GO/PI-based graphite fibres was calculated according to the following empirical formula: ${ }^{33}$

$$
\lambda=1261 / \rho
$$

herein, $\lambda$ is the thermal conductivity $\left(\mathrm{W} \mathrm{m}^{-1} \mathrm{~K}^{-1}\right)$ of GFs, and $\rho$ is the electrical conductivity $\left(\mu \Omega \mathrm{m}^{-1}\right)$ of GFs.

\section{Results and discussion}

\section{Chemical structure and morphology of the PI fibres and GO/PI composite fibres}

As shown in Fig. 1, the two-adjacent peaks around $1718 \mathrm{~cm}^{-1}$ and $1776 \mathrm{~cm}^{-1}$ demonstrate the formation of an imide group and the five-membered cyclic structure of polyimide, accompanied by the disappearance of amide groups at $1550 \mathrm{~cm}^{-1}$. The sharp peak at $1373 \mathrm{~cm}^{-1}$ represents the stretching vibration peak of the $\mathrm{C}-\mathrm{N}$ bond, and the sharp peak at $721 \mathrm{~cm}^{-1}$ represents the bending vibration of the $\mathrm{C}=\mathrm{O}$ bond, which together indicate the formation of polyimide. The sharp peak at $1250 \mathrm{~cm}^{-1}$ shows the existence of an ether group in the molecular chains.

With an increase in the GO content in the composite fibre, the intensity of the stretching vibration peak of $\mathrm{OH}$ group increased. The smaller peak at $1250 \mathrm{~cm}^{-1}$ represents the stretching vibration peak of the $\mathrm{C}-\mathrm{O}-\mathrm{C}$ bond, which indicates excellent flexibility of the molecular chains. The peak at $1715 \mathrm{~cm}^{-1}$ represents the $\mathrm{C}-\mathrm{C}=\mathrm{O}$ bond, and the peak at $1500 \mathrm{~cm}^{-1}$ represents benzene. An increase in the intensity ratio of benzene bond and $\mathrm{C}-\mathrm{C}=\mathrm{O}$ bond indicates the reaction of $\mathrm{GO}$ and PI molecular chains. It can be inferred that the PI molecular

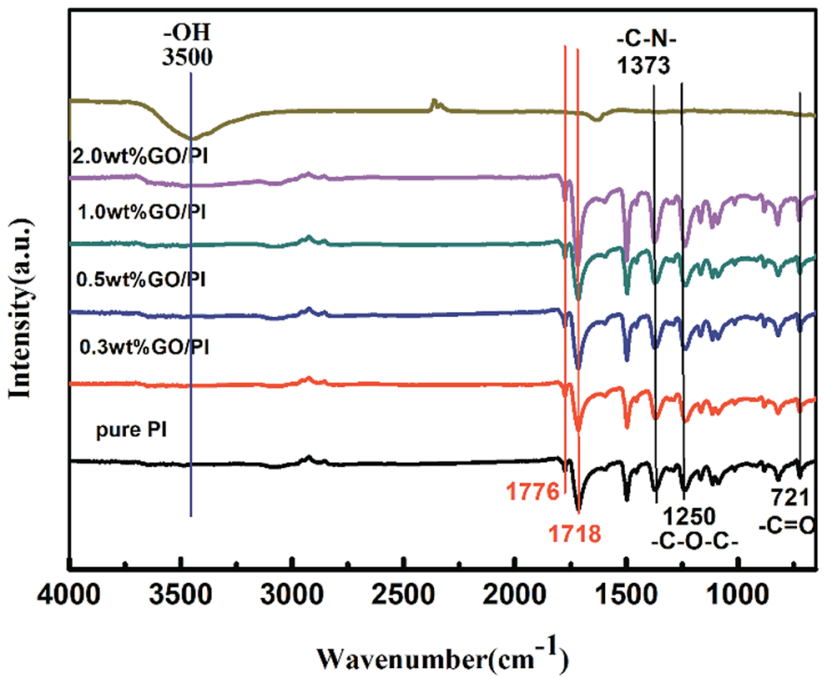

Fig. 1 FTIR spectrum of the pure PI and GO/PI fibres with different GO contents.

chains are fixed on the surface of the GO sheet due to $\pi-\pi$ conjugation. The orientation of the GO sheet can be controlled to be along the fibre axis during the spinning process. Moreover, the orientation of the PI molecular chains can be induced to be along the fibre axis.

Fig. 2 shows the surface and cross-sectional morphology of GO/PI-based graphite fibres with different GO contents. As shown in the images (A and B), the surface of pure PI is quite smooth, and the cross-section images shows that it has several holes on it; this indicates the brittle fracture of the pure PIbased graphite fibres. The images $\mathrm{C}$ and $\mathrm{D}$ show the surface and cross-sectional morphology of the $0.3 \mathrm{wt} \% \mathrm{GO} / \mathrm{PI}-$ based graphite fibre. The magnified parts of the image $\mathrm{C}$ show several grooves on the surface of the fibre along the fibre axis; this indicates that addition of GO can improve the orientation of the graphite fibre. From image D, it is clear that the surface of the 0.3 wt\% GO/PI-based graphite fibre is rough; thus, the mechanical quality of the composite fibre is high. For the $2.0 \mathrm{wt} \% \mathrm{GO} / \mathrm{PI}$ composite graphite fibres, the grooves on its surface become wider, and cross-sectional parts become rougher.

\section{Thermal stability of the PI fibre and GO/PI composite fibre}

TG-DSC analysis was carried out under nitrogen for investigating the thermal stability of the PAA fibres and GO/PAA fibres. From room temperature to $150{ }^{\circ} \mathrm{C}$, both the PAA fibres and $\mathrm{GO} /$ PAA fibres experienced a $5 \%$ weight loss, which was probably because of solvent evaporation inside the fibres. From $150{ }^{\circ} \mathrm{C}$ to $220^{\circ} \mathrm{C}$, both the PAA fibres and GO/PAA fibres experienced an obvious weight loss of about $20-30 \%$, which indicates that the PAA fibres change into aromatic PI fibres. Then, the PI fibres experienced about $30 \%$ weight loss above $500{ }^{\circ} \mathrm{C}$, which indicates that the aromatic structure turns into amorphous carbon. Form $150{ }^{\circ} \mathrm{C}$ to $700{ }^{\circ} \mathrm{C}$, the residual weight of the GO/PAA fibres is higher than that of the PAA fibres; this indicates that doping 

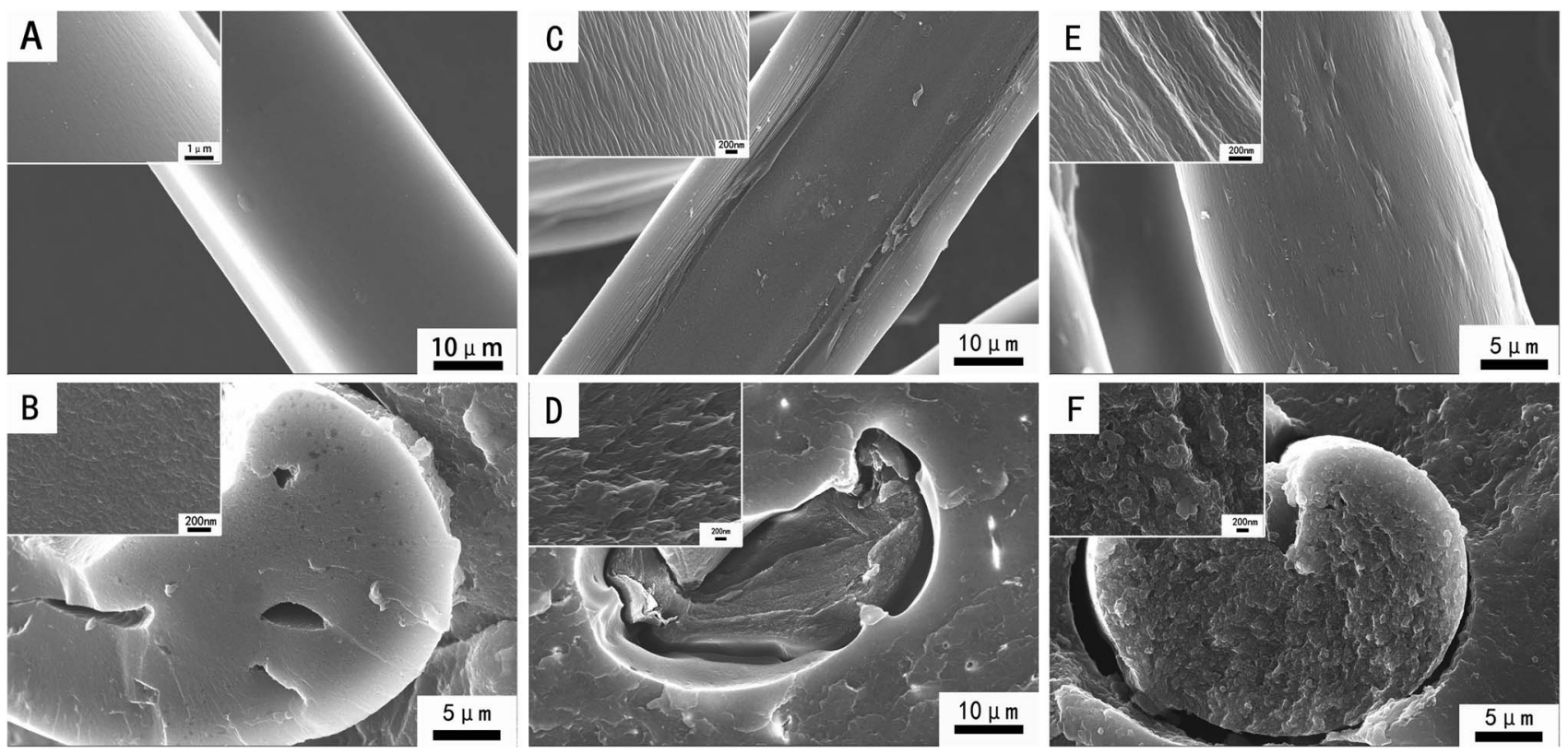

Fig. 2 Surface and cross-sectional morphology of the graphite fibres based on (A and B) pure PI, (C and D) 0.3 wt\% GO/PI, (E and F) 2.0 wt\% $\mathrm{GO} / \mathrm{PI}$.

of GO improves the thermal stability of the GO/PAA fibres. However, the residual weight of the GO/PAA fibre was lower than that of the PAA fibres above $700{ }^{\circ} \mathrm{C}$; this was mainly because doping of GO increased the decomposition rate of the GO/PAA fibres.

PI fibres are a kind of high-temperature resistant polymer fibres, which are mainly used in a flame retardant area. The TGDSC analysis of the PI fibres and GO/PI fibres was carried out in air. Fig. 3 demonstrates the thermal stability of the pure PI fibres and GO/PI composite fibres with different GO contents. As shown in Fig. 3, the 10\% weight loss temperature of the GO/ PI composite fibre with $1.0 \mathrm{wt} \% \mathrm{GO}$ is $509{ }^{\circ} \mathrm{C}$, which is nearly $40^{\circ} \mathrm{C}$ higher than that of the pure PI fibre. From Fig. 3, we can observe that the initial decomposition temperature of the GO/PI

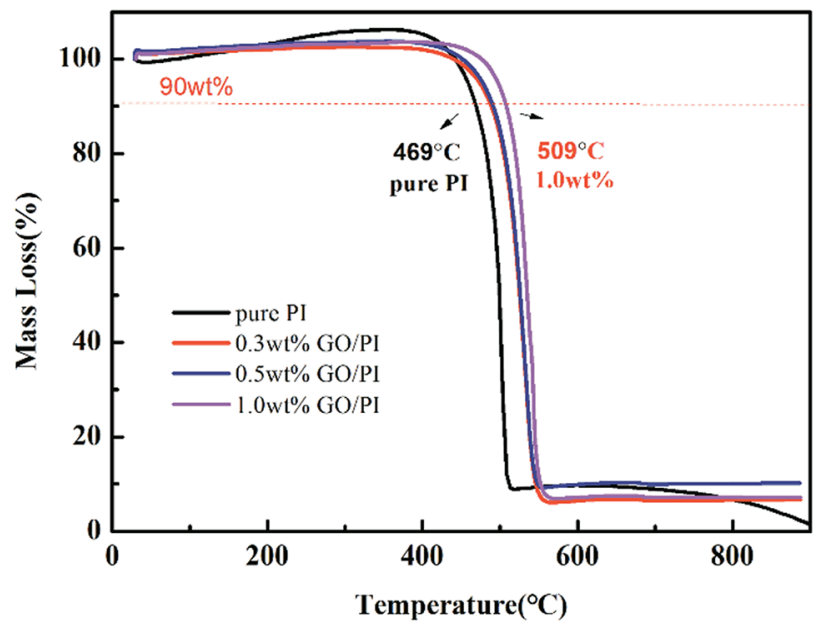

Fig. 3 TG curves of the pure PI fibres and GO/PI composite fibres. composite fibre is higher than that of the pure PI fibres; this indicates that GO doping can increase the thermal stability of the GO/PI fibres. Fig. 4 shows the DSC curves of the PI fibres and $\mathrm{GO} / \mathrm{PI}$ composite fibres.

From Fig. 4, it can be clearly observed that the GO/PI composite fibre with $1 \mathrm{wt} \%$ GO has a exothermic peak temperature and lower exothermic peak intensity than that of the pure PI fibre. The exothermic peak temperature of the GO/PI composite fibre with $1 \mathrm{wt} \% \mathrm{GO}$ added increases by $7 \%$ than that of the pure PI fibre, and the exothermic intensity drops by $69.7 \%$. It can be inferred that the addition of GO can effectively increase the thermal stability and decrease the exothermic heat of GO/PI fibres during the carbonization process. The reason

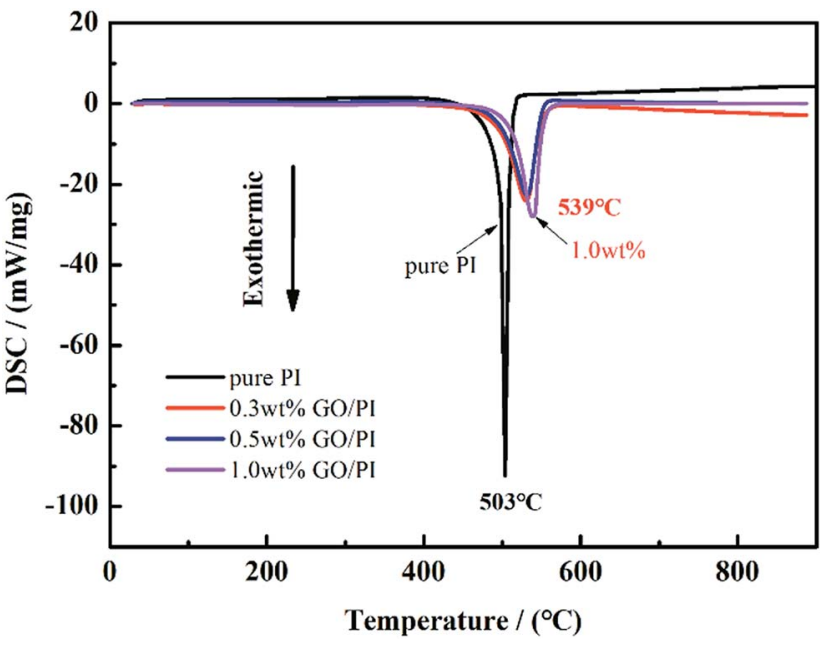

Fig. 4 DSC curves of the pure PI fibres and GO/PI composite fibres. 
why doping of GO can improve the thermal stability and decrease the exothermic heat can be inferred for the following two reasons. First, GO sheets have a strong interaction with PI molecular chains and may form a crosslinking structure, which greatly decreases the heat released during carbonization. Second, GO sheets can hinder the movement of the PI molecular chains; this increases the energy needed to break the PI molecular chains.

\section{Crystalline structure of PI-based graphite fibres and GO/PI composite graphite fibres}

Fig. 5 displays the diffraction patterns of the GO/PI-based graphite fibres with different GO contents. The diffraction peak around $26^{\circ}$ indicates the development of (002) planes. The existence of the (004) peak indicates the formation of a graphite structure. With the increase of the GO content, the diffraction angle of (002) moved to a higher degree; this indicated the decrease of $d_{002}$, revealing that doping of GO could induce crystallization. The value of $d_{002}$ of the graphite fibre with $2.0 \mathrm{wt} \% \mathrm{GO}$ is $0.3392 \mathrm{~nm}$, which is very close to that of the ideal graphite crystal $(0.3354 \mathrm{~nm})$. As shown in Table 1 , both the average crystallite size $L_{\mathrm{a}}$ and the average crystallite thickness $L_{\mathrm{c}}$ were increased with the increase of the GO content; this indicated that doping of GO could induce the growth of graphite crystallite.

It can be inferred that GO with a large surface area acts as a crystal nucleus, which can induce the crystallization of graphite fibres. As abovementioned, the PI molecular chains were attached to the graphene sheets and then graphitized to the graphene net during the graphitization process. As the process of graphitization carrys on, the layer of graphene sheets grows; this indicates the formation of graphite crystallites. The degree of graphitization increased as the GO content raised; this proved our speculation. The increase of graphitization could be confirmed by Raman spectroscopy.

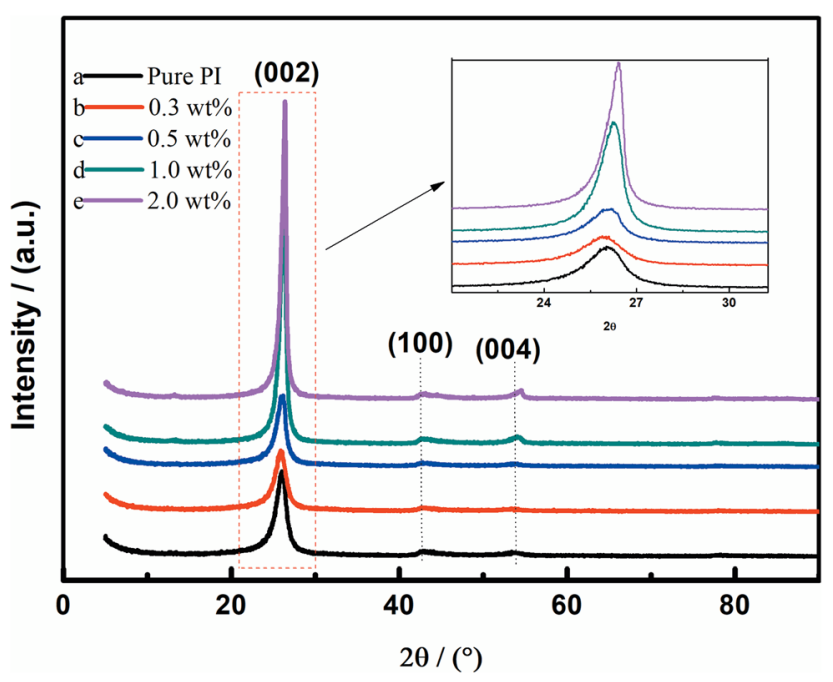

Fig. 5 XRD curves of the GO/PI-based graphite fibres with different GO contents.
Table 1 The result of XRD analysis of the GO/PI-based graphite fibres ${ }^{a}$

\begin{tabular}{lllccl}
\hline Sample & $2 \theta\left(^{\circ}\right)$ & $d_{002}(\mathrm{~nm})$ & $L_{\mathrm{a}}(\mathrm{nm})$ & $L_{\mathrm{c}}(\mathrm{nm})$ & $G(\%)$ \\
\hline PI & 25.83 & 0.3449 & 5.73 & 12.63 & - \\
$0.3 \mathrm{wt} \% \mathrm{GO} / \mathrm{PI}$ & 25.92 & 0.3437 & 5.99 & 13.18 & 3.5 \\
$0.5 \mathrm{wt} \% \mathrm{GO} / \mathrm{PI}$ & 25.93 & 0.3436 & 6.72 & 14.77 & 4.6 \\
$1.0 \mathrm{wt} \% \mathrm{GO} / \mathrm{PI}$ & 26.16 & 0.3407 & 10.62 & 23.10 & 38.4 \\
$2.0 \mathrm{wt} \%$ GO/PI & 26.27 & 0.3392 & 13.47 & 29.19 & 55.8
\end{tabular}

${ }^{a} L_{\mathrm{a}}$ represents the average size of crystallite, and $L_{\mathrm{c}}$ stands for the average crystallite thickness.

Laser Raman spectrum was used to examine the crystallite structure of the graphite fibre with different GO contents. For carbon materials, the $\mathrm{D}$ band is caused by the defects and disorder, whereas the $\mathrm{G}$ band is caused by the stretching of all $\mathrm{sp}^{2}$ bonding atoms. For the graphite material, the value of $R=$ $I_{\mathrm{D}} / I_{\mathrm{G}}$ is positive, related to the size of graphite crystallites, which can be used to represent the degree of graphitization. The lower the value of $R$, the higher the degree of graphitization. During the graphitization process, $\mathrm{GO}$ as a crystal nucleus could induce the formation of graphite crystallites. As shown in Fig. 6, the value of $R$ increased with the addition of GO; this indicated the increase of the graphitization degree (Table 2).

Fig. 7 displays the orientation curves of the GO/PI-based carbon fibres and graphite fibres were obtained using XRD. Both the value of $\pi$ and the value of $\phi$ indicate the orientation degree of the graphite fibre. With an increase in the heat treatment temperature from $1000{ }^{\circ} \mathrm{C}$ to $2800{ }^{\circ} \mathrm{C}$, the value of $\pi$ increases by $23.3 \%$; this indicates that high temperature treatment can improve the orientation of the graphite fibre. The orientation degree of the GO/PI-based graphite fibre with $0.3 \mathrm{wt} \% \mathrm{GO}$ added is higher than that of the pure PI fibre; this indicates that GO can promote fibre orientation.

The orientation of the GO/PI-based graphite fibres was examined by XRD. A bunch of aligned graphite fibres were fixed

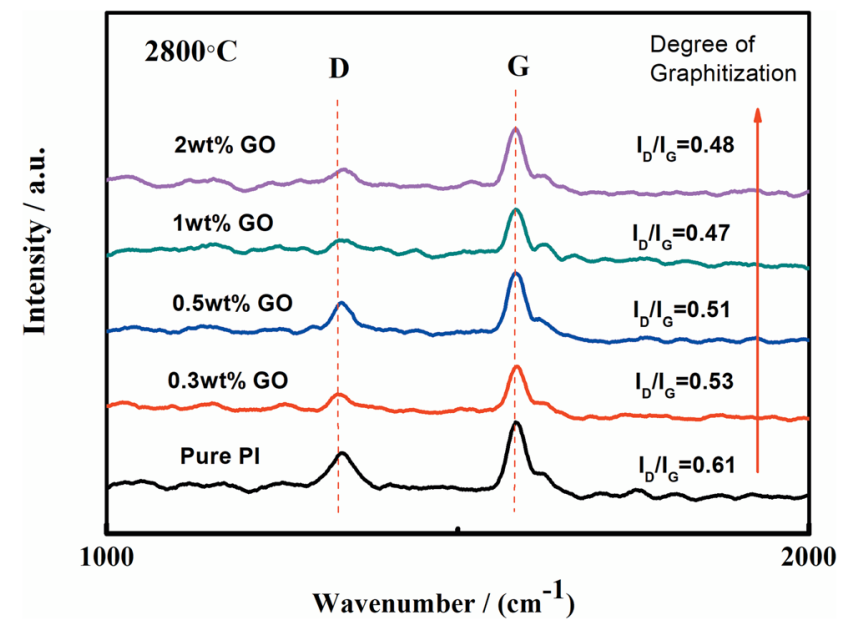

Fig. 6 Raman spectrum of GO/PI-based graphite fibres with different GO contents. 
Table 2 The result of orientation curves analysis of the GO/PI-based graphite fibres

\begin{tabular}{lllll}
\hline Sample & $\mathrm{HTT} /{ }^{\circ} \mathrm{C}$ & FWHM & $\pi /{ }^{\circ}$ & $\phi$ \\
\hline PI & 1000 & 64.30 & 64.28 & 57.85 \\
& 2800 & 41.96 & 76.69 & 69.02 \\
$0.3 \mathrm{wt} \%$ GO/PI & 1000 & 52.21 & 70.99 & 63.90 \\
& 2800 & 33.51 & 81.38 & 73.25
\end{tabular}

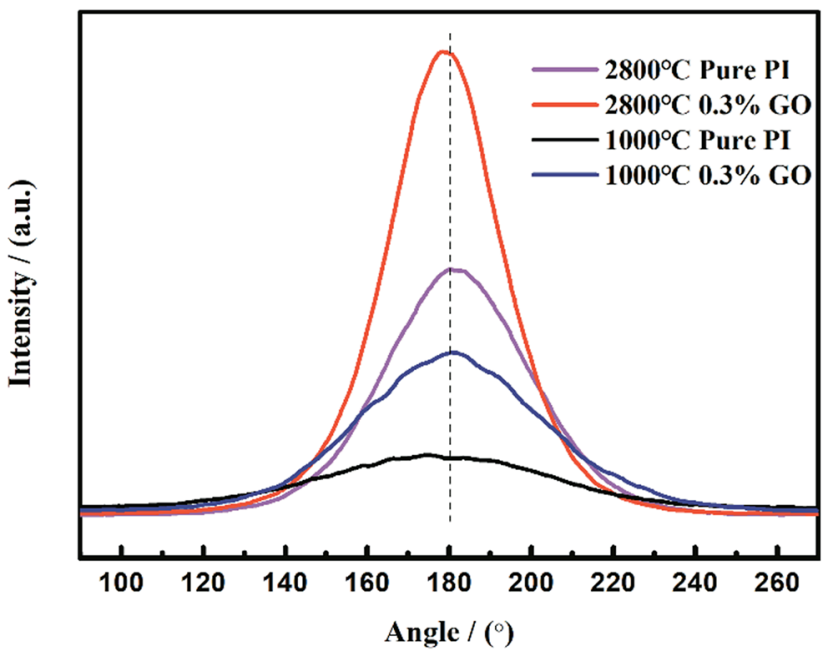

Fig. 7 The orientation curves of the GO/PI-based graphite fibers.

to the sample cell at both ends, with the fibre length less than 5 $\mathrm{mm}$. The samples were placed perpendicular to the X-ray, and the counter tube is placed at the maximum intensity of the (002) diffraction peak. Upon rotating the sample station in all directions, the reflected intensity was determined to obtain the diffraction pattern with the highest intensity of the meridian. The orientation degree $\pi$ can be calculated according to the value of the full width at half maximum (FWHM):

$$
\pi=\frac{180-H}{180} \times 100 \%=\frac{180-2 Z}{180} \times 100 \%(H=2 \times Z)
$$

Herein, $H$ represents the value of FWHM, and $Z$ represents the orientation angle.

For the graphite fibre, a certain angle between the normal direction of the microcrystalline plane and the fibre orientation axis is called $\varphi$. The angle $\varphi$ is used to characterize the degree of orientation. The higher the value of this angle, the better the orientation.

$$
\varphi=90-Z
$$

As abovementioned, GO can promote the orientation of the as-spun PAA fibres. The PI molecular chains were attached to the GO sheets according to the $\pi-\pi$ interaction. The orientation of GO sheets was forced to be along the fibre axis due to the strong shear force during the spinning process; this allowed the PI molecular chains to form along the fibre axis at the same time. During the carbonization and graphitization process, GO acts as a crystal nucleus and can induce the proper arrangement of graphite microcrystals, thus improving the orientation of the graphite fibre.

\section{Mechanical property and thermal conductivity of the graphite fibre}

Fig. 8 shows the tensile strength and breaking elongation of $\mathrm{GO} /$ PI-based graphite fibres with different GO contents. From Fig. 8, it is clear that the breaking elongation decreases with the addition of GO, and the tensile strength decreases beyond that at $0.3 \mathrm{wt} \%$ with the addition of GO. The tensile strength of $0.3 \mathrm{wt} \%$ GO-added graphite fibre is $693.89 \mathrm{MPa}$, which increases by $67.7 \%$ as compared to that of the pure PI-based graphite fibre, whereas the tensile strength of $0.5 \mathrm{wt} \%$ GO decreases by $37.2 \%$ as compared to that of $0.3 \mathrm{wt} \%$ GO. It can be inferred that the mechanical quality of the GO/PI composite graphite fibre can be improved by adding a certain amount of GO. If too much GO is added, the mechanical properties of graphite fibre will decrease since GO cannot disperse well in the fibre. The over added GO will aggregate in the fibre and form defects, which can limit the property of the fibre. Moreover, with an increase in the GO content, the breaking elongation of the graphite fibre decreases; this indicates the increase of tensile modules of graphite fibre. Due to the improvement of fibre orientation, the mechanical properties of the composite graphite fibre was improved as well.

The electrical resistance and thermal conductivity of the mesophase carbon fibre has an empirical equation, which is $\lambda=$ $1261 / \rho$ ( $\lambda$ represents the thermal conductivity, and $\rho$ represents the electric resistivity). A resistivity meter was used to measure the electrical resistance, and then, the thermal conductivity was calculated according to the equation. As shown in Fig. 9, the thermal conductivity increased with the addition of GO. The thermal conductivity of the GO/PI-based graphite fibre with $2.0 \mathrm{wt} \%$ GO content is $435.5 \mathrm{~W} \mathrm{~m}^{-1} \mathrm{~K}^{-1}$ and is $81.2 \%$ higher than that of the pure PI-based graphite fibre. The increased thermal conductivity of the composite graphite fibre may due to two reasons: the first reason is that the orientation along the

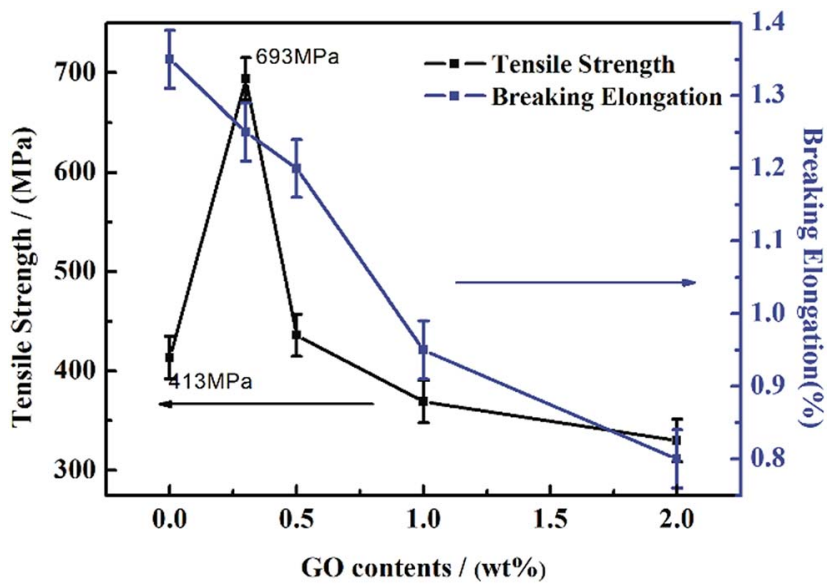

Fig. 8 Tensile strength and breaking elongation of the GO/PI-based graphite fibres with different GO contents. 


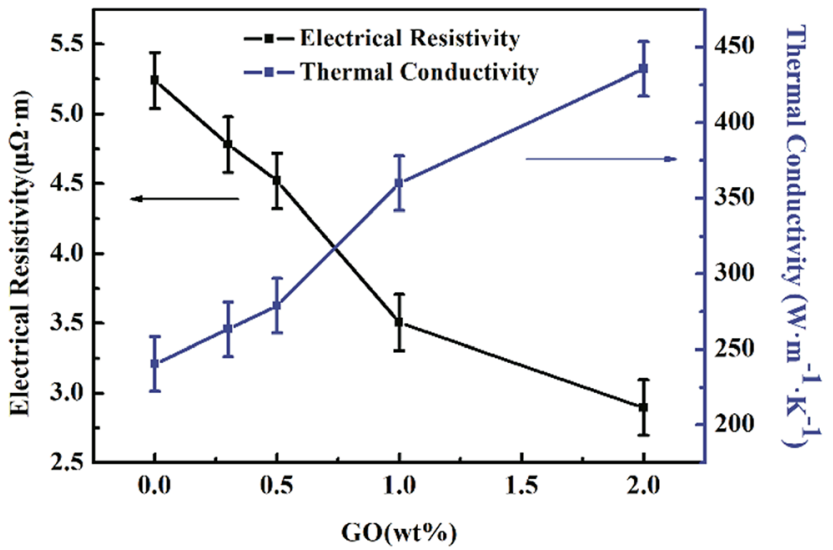

Fig. 9 The thermal conductivity of GO/PI-based graphite fibre with different GO contents.

fibre axis is improved during the spinning process and the beginning of carbonization process, another reason is that GO addition has induced the crystallization of the graphite fibre. Still, we need to find a balance between good mechanical property and high thermal conductivity. It can be reasonably believed that PI fibres are an ideal carbon precursor to prepare graphite fibre with high thermal conductivity.

\section{Conclusions}

The influences of addition of GO on the structure and properties of a GO/PI-based graphite fibre were carefully studied. In our study, we prepared graphite fibres with different GO contents and used different methods, such as FTIR spectroscopy, TG-DSC, XRD, and Raman spectroscopy, to characterize graphite fibres. Through a series of identification tests, it was found that the addition of GO can improve the orientation along the fibre axis and increase the degree of graphitization; thus, we can obtain a graphite fibre with a high mechanical property and high thermal conductivity. According to the TGDSC curves, a GO/PI-based graphite fibre with $1 \mathrm{wt} \%$ GO addition has a $7 \%$ higher exothermic peak temperature and $69.7 \%$ lower exothermic peak intensity than the pure PI fibre; this indicates that doping of GO can improve the thermal stability and therefore maintain the preferred orientation of the graphite fibre. XRD and Raman curves indicate that doping of GO can increase the degree of graphitization of the graphite fibre because GO sheets act as a nucleus crystal during the graphitization process. GO can improve the orientation of the GO/PI composite fibres during the spinning process and maintain the preferred orientation during the beginning process of carbonization; thus, we can fabricate a graphite fibre with higher mechanical properties and thermal conductivity. Although the increase of graphitization degree can increase the thermal conductivity of the graphite fibre, it will decrease the mechanical properties of the graphite fibre. It is better to have a balance between mechanical properties and thermal conductivity, and we found that $0.3 \mathrm{wt} \%$ addition amount of GO is a better choice. In this study, we introduced a new approach to prepare graphite fibres with high thermal conductivity from PI fibres, and these fibres have potential application in heat management areas.

\section{Conflicts of interest}

There are no conflicts of interest to declare.

\section{Acknowledgements}

The author gratefully acknowledge the financial support of National Natural Science Foundation of China (NSFC, Project U1610252). The author greatly thanks Jia Sheng for her discussion regarding this study and his parents for their support. Thanks to Ms Liu, Shasha Guo, Wei Chen for their efforts in carrying out the XRD, TG-DSC, and SEM analysis on the samples.

\section{Notes and references}

1 P. Kumar, S. Yu, F. Shahzad, S. M. Hong, Y.-H. Kim and C. M. Koo, Carbon, 2016, 101, 120-128.

2 F. Wei, Q. Mengmeng and Y. Feng, Carbon, 2016, 109, 575597.

3 A. Bürger, E. Fitzer, M. Heym and B. Terwiesch, Carbon, 1975, 13, 149-157.

4 M. Inagaki, N. Ohta and Y. Hishiyama, Carbon, 2013, 61, 121.

5 L. Peng, Z. Xu, Y. Guo, P. Li and C. Gao, Adv. Mater., 2017, 29(27), DOI: 10.1002/adma.201700589.

6 Y. Hishiyama, K. Igarashi, I. Kanaoka, H. Fujii, T. Kaneda, T. Koidesawa, Y. Shimazawa and A. Yoshida, Carbon, 1997, 35, 657-668.

7 S.-H. Hsiao and Y.-J. Chen, Eur. Polym. J., 2002, 38, 815-828. 8 T. Tsutomu, T. Hidehiro, O. Satoshi and I. Michio, J. Appl. Polym. Sci., 2010, 54(3), 361-365.

9 T. Takeichi, Y. Kaburagi, Y. Hishiyama and M. Inagaki, Carbon, 1995, 33, 1621-1625.

10 Y. Kaburagi, A. Yoshida, H. Kitahata and Y. Hishiyama, Carbon, 1996, 34, 1455.

11 C. Kim, K. Hakamada and M. Endo, Carbon, 1998, 36, 14011403.

12 G. Marletta, F. Iacona and A. Toth, Macromolecules, 1992, 25, 3190-3198.

13 M. Inagaki, H. Tachikawa, T. Nakahashi, H. Konno and Y. Hishiyama, Carbon, 1998, 36, 1021-1025.

14 Y. Isono, A. Yoshida, Y. Hishiyama and Y. Kaburagi, Carbon, 2004, 42, 1799-1805.

15 Y. Suhng, K. Hashizume, T. Kaneko, S. Otani and S. Yoshimura, Synth. Met., 1995, 71, 1751-1752.

16 G. S. Bhat and R. Schwanke, J. Therm. Anal., 1997, 49, 339405.

17 G. S. Bhat and R. Schwanke, American Carbon Society, 1997, pp. 406-407.

18 A. Li, Z.-K. Ma, H.-H. Song, N. Li and M.-Y. Hou, RSC Adv., 2015, 5, 79565-79571. 
19 A. Li, Z.-K. Ma, H.-H. Song, K. Lu, Z.-J. Liu and Q.-G. Guo, Carbon, 2015, 85, 447.

20 M. Y. Zhang, H. Q. Niu, S. L. Qi, G. F. Tian, X. D. Wang and D. Z. Wu, Mater. Today Commun., 2014, 1, 1-8.

21 D. Cai and M. Song, J. Mater. Chem., 2010, 20, 7906.

22 R. Verdejo, M. M. Bernal, L. J. Romasanta and M. A. LopezManchado, J. Mater. Chem., 2011, 21, 3301-3310.

23 W. S. Hummers and R. E. Offeman, J. Am. Chem. Soc., 1958, 80, 1339.

24 J.-Y. Wang, S.-Y. Yang, Y.-L. Huang, H.-W. Tien, W.-K. Chin and C.-C. M. Ma, J. Mater. Chem., 2011, 21, 13569.

25 L.-B. Zhang, J.-Q. Wang, H.-G. Wang, Y. Xu, Z.-F. Wang, Z.-P. Li, Y.-J. Mi and S.-R. Yang, Composites, Part A, 2012, 43, 1537-1545.

26 B. Hua, L. Chun and S. Gaoquan, Adv. Mater., 2011, 23, 10891115.
27 J. Zhu, J. Lim, C.-H. Lee, H.-I. Joh, H. C. Kim, B. Park, N.-H. You and S. Lee, J. Appl. Polym. Sci., 2014, 131(9), DOI: 10.1002/app.40177.

28 T. Huang, R. Lu, C. Su, H. Wang, Z. Guo, P. Liu, Z. Huang, H. Chen and T. Li, ACS Appl. Mater. Interfaces, 2012, 4, 2699-2708.

29 M. Chen, J. Yin, R. Jin, L. Yao, B. Su and Q. Lei, Thin Solid Films, 2015, 584, 232-237.

30 J. Dong, C. Yin, X. Zhao, Y. Li and Q. Zhang, Polymer, 2013, 54, 6415-6424.

31 T. Kaneda, T. Katsura, K. Nakagawa and H. Makino, J. Appl. Polym. Sci., 1986, 32(1), 3133-3149.

32 T. Kaneda, T. Katsura, K. Nakagawa and H. Makino, J. Appl. Polym. Sci., 1986, 32(1), 3151-3176.

33 X. Zhang, S. Fujiwara and M. Fujii, Int. J. Thermophys., 2000, 21, 965-980. 